\title{
Papers
}

\section{Expression profile of human herpesvirus 8 (HHV-8) in pyothorax associated lymphoma and in effusion lymphoma} M O’Donovan, I Silva, V Uhlmann, N Bermingham, K Luttich, C Martin, O Sheils,
A Killalea, C Kenny, S Pileri, J J O'Leary

\begin{abstract}
Aims-Pyothorax associated lymphoma (PAL) occurs in a clinical setting of longstanding pyothorax or chronic inflammation of the pleura. Like primary effusion lymphoma, it has an association with Epstein-Barr virus (EBV), and is confined to the pleural cavity, but has differing morphological and phenotypic features. Human herpesvirus 8 (HHV-8) has been consistently reported in primary effusion lymphoma. This study examines the immunophenotype of two European cases of PAL, investigates the presence of HHV-8 and its expression profile, and assesses whether PAL is similar to other effusion lymphomas.
\end{abstract}

Methods-Material was obtained from two European cases of PAL. Immunocytochemical analysis was performed using antibodies against CD45, CD20, CD79a, CD45RAA, CD3, CD43, CD45RO (UCHL1), CD30, BCL-2, CD68, epithelial membrane antigen (EMA), BCL-6, p53, Ki-67, $\kappa$ light chain, $\lambda$ light chain, and the EBV antigens latent membrane protein 1 (LMP-1) and EBV encoded nuclear antigen 2 (EBNA-2). The cases were examined for HHV-8 by means of polymerase chain reaction in situ hybridisation (PCR-ISH), solution phase PCR, in situ hybridisation (ISH), and real time quantitative TaqMan PCR to HHV-8 open reading frame 26 (ORF-26) and viral (v) cyclin encoding regions. The expression profile of $\mathrm{HHV}-8$ in PAL and in BC-1 and BC-3 cells was assessed by RNA TaqMan PCR to the HHV-8 genes encoding v-cyclin, v-IL-6, and $G$ protein coupled receptor (GPCR). Results-Both cases expressed CD24, CD20, CD79a, BCL-2, light chain restriction, and high Ki-67 staining. EBV was identified by EBER-ISH in one case. HHV-8 was not identified by solution phase PCR, but was detected by PCR-ISH (sensitivity of 1 viral genome copy/cell) in $35 \%$ of the cells and by TaqMan PCR, which showed 50-100 HHV-8 copies $/ 2000$ cell genome equivalents (sensitivity of 1 viral genome in $10^{6}$ contaminating sequences). HHV-8 v-IL-6, v-cyclin, and GPCR encoded transcripts were identified using RNA TaqMan PCR. v-IL-6 was high in PAL and in BC-1 and BC-3 cells.

Conclusion-The presence of $\mathrm{HHV}-8$ in one of two patients with PAL raises interesting questions in relation to the pathobiology of the condition. Clearly, the results indicate that HHV-8 is not an obligate pathogen, necessary for the effusion phenotype, but might contribute to it by its secretion of specific cytokines.

(f Clin Pathol: Mol Pathol 2001;54:80-85)

Keywords: pyothorax associated lymphoma; human herpesvirus 8; primary effusion lymphoma

Pyothorax associated lymphoma (PAL) is a relatively recently described entity, occurring most frequently in Japanese populations, ${ }^{1-4}$ with occasional cases reported in Western countries..$^{5-11}$ Patients have a clinical history of longstanding pyothorax or chronic inflammation of the pleura, resulting from the artificial induction of pneumothorax for the treatment of tuberculosis or tuberculous pleuritis. PAL occurs between 22 and 55 years after the onset of pulmonary tuberculosis. Patients present with chest pain, pleural effusion, and/or a mass with infiltration of the visceral or parietal pleura. Histologically, tumours have a diffuse large cell morphology with many showing immunoblastic differentiation. Tumour cells are B cells or null cells, are CD30 negative, and exhibit monoclonal immunoglobulin gene rearrangements. Most cases show Epstein-Barr virus (EBV) infectivity, with EBV encoded early RNA 1 (EBER1) and EBER2 positivity, strong expression of EBV encoded nuclear antigen 2 (EBNA-2) and weak expression of latent membrane protein 1 (LMP-1). ${ }^{8-10}{ }^{12-14}$ Although PALs and primary effusion lymphomas have a similar pleural location and association with EBV, they have different morphological and phenotypic features. Human herpesvirus 8 (HHV-8) has recently been reported in association with primary effusion lymphomas (body cavity based lymphomas), and this has led to speculation regarding its 
involvement in PALs. To date, Ascani et al have been the only group to identify HHV-8 in their small series of pyothorax associated lymphomas. ${ }^{11}$ Here, we analyse two European cases of PAL for HHV-8 using the highly sensitive TaqMan technique. The objective of our study was to examine the immunophenotypic profile of European cases of PAL, to examine the expression patterns of EBV infection in these cases, and to assess whether HHV-8 is associated with PAL as it is with other effusion lymphomas.

\section{Materials and methods}

Material from two patients with PAL was obtained from the files of the Department of Haematology, University of Bologna, Italy.

Patient 1 was a 70 year old man who had a history of artificial pneumothorax for pulmonary tuberculosis 50 years previously. A computed tomography scan showed a tumoral mass continuous with the pleura and invading the chest wall. Biopsy histology showed this to be a diffuse peripheral large B cell lymphoma, immunoblastic type (REAL classification).

Patient 2 was a 75 year old man with a history of artificial pneumothorax for pulmonary tuberculosis; 45 years previously he presented with a $15 \mathrm{~cm}$ mass in the left anterior hemithorax. Biopsy histology showed a diffuse peripheral large B cell lymphoma, immunoblastic type.

Immunocytochemical analysis was performed using the APAAP technique. Antibodies were used against CD45 (Dako, Glostrup, Denmark), CD20, CD79a (Dr DY Mason, Oxford, UK), CD45RA (Dako), $\kappa$ light chain (polyclonal; Dako), $\lambda$ light chain (polyclonal; Dako), CD3, CD43 (Dako), CD45RO (UCHL1) (Dako), CD30, BCL-2, p53 (Dako), BCL-6 (Professor B, Falini, Perugia, Italy), Ki-67 (Professor J Gerdes, Borstel, Germany), CD68 (Professor Falini), EMA (Dako), and the EBV antigens LMP-1 and EBNA-2 (Dako). Immunocytochemical detection was achieved using the manufacturers' recommendations.

EBV was detected using EBER-ISH (DAKO) and solution phase PCR. ${ }^{11}$

Immunoglobulin gene rearrangement was assessed. DNA was extracted from paraffin wax embedded tissue blocks and amplified by the PCR based method for the detection of rearranged immunoglobulin heavy chain genes described by Ramasamy et al. ${ }^{15}$ Primers homologous to the conserved sequences of the framework II and III regions, as well as the LJH and VLJH regions, were used.

HHV-8 was detected using non-isotopic in situ hybridisation, PCR-ISH, solution phase PCR, and TaqMan quantitative PCR.

HHV-8 DETECTION BY PCR ISH

Sections ( $5 \mu \mathrm{m}$ thick) were cut on to silane coated in situ PCR glass slides (PE Biosystems, Warrington, UK). BC-1 and BC-3 cells established from patients with effusion lymphomas (containing 50-80 HHV-8 genome equivalents) were used as positive controls. Tissue sections were dewaxed with xylene for $15 \mathrm{~min}$ utes, and $100 \%$ ethanol for 10 minutes, followed by incubation in $0.02 \mathrm{~N} \mathrm{HCl}$ for 10 minutes and digestion with $0.4 \mathrm{mg} / \mathrm{ml}$ proteinase $\mathrm{K}$ at $37^{\circ} \mathrm{C}$ for 15 minutes. Proteinase $\mathrm{K}$ was removed by washing the sections in cold phosphate buffered saline (PBS). Endogenous peroxidase activity was blocked with a $3 \%$ hydrogen peroxide solution in $0.1 \%$ sodium azide. PCR amplification was carried out using the Gene Amp in situ PCR 1000 system (PE Biosystems). The following reaction conditions were used: $1 \mu \mathrm{M}$ of each HHV-8 primer (KS1 open reading frame 26 (ORF-26): 5'AGCCGAAAGGATTCCAC CAT-3' and KS2 ORF-26: 5'-TCCGTGTT GTCTACGTCCAG-3'), $200 \mu \mathrm{M}$ dNTPs, 4-5 mM MgCl${ }_{2}, 1 \times$ PCR buffer II (PE Biosystems), and $10 \mathrm{U}$ Taq IS (PE Biosystems) in a total reaction volume of $50 \mu \mathrm{l}$. Slides were assembled on the in situ PCR 1000 slide assembly unit (PE Biosystems), which was held at $70^{\circ} \mathrm{C}$ to perform "hot start" PCR. An aliquot of $50 \mu \mathrm{l}$ of the PCR mix was placed directly on to the tissue sections and the reaction mix was covered with AmpliCover discs and clips (PE Biosystems). The slides were transferred to the heating block and the following cycles applied: $94^{\circ} \mathrm{C}$ for 55 seconds (cycle 1), followed by $94^{\circ} \mathrm{C}$ for 50 seconds and $55^{\circ} \mathrm{C}$ for 90 seconds for a total of 30 cycles. Control sections from each sample were used for PCRISH , without Taq polymerase and/or without primers. After amplification, AmpliCover discs and clips were removed and slides were fixed in $100 \%$ ethanol for five minutes. For HHV-8 detection, a 5 '-end biotin labelled $30 \mathrm{mer}$ oligoprobe (5'-TGTTGGTGTACCACAT CTACTCCAAAATAT-3'; Oswell, Edinburgh, UK), which hybridises internally to the PCR amplicon, was applied at a concentration of 5-10 pmol/100 $\mu \mathrm{l}$ hybridisation buffer (5\% dextran sulphate, $2 \times$ saline sodium citrate (SSC), and $10 \%$ formamide) to the centre of each section, which was then covered with a glass coverslip.

Slides were denatured at $94^{\circ} \mathrm{C}$ for 15 minutes and then hybridised for 12 hours at $42^{\circ} \mathrm{C}$. The coverslips were removed and the slides washed in SSC at different stringencies ( $4 \times$ SSC at $22^{\circ} \mathrm{C}$ for 15 minutes, $2 \times$ SSC at $55^{\circ} \mathrm{C}$ for 15 minutes, or $1 \times \mathrm{SSC}$ at $55^{\circ} \mathrm{C}$ for 15 minutes), followed by a final wash in TBT (100 nM NaCl, $40 \mathrm{mM}$ Tris (pH 7.2), 3\% bovine serum albumin (BSA), and $0.05 \%$ Triton X-100) for 10 minutes. Target specific signals were seen with washing stringencies of $2 \times$ SSC at $30^{\circ} \mathrm{C}$ and $2 \times \mathrm{SSC}$ at $55^{\circ} \mathrm{C}$. Only occasionally were signals seen at $1 \times \mathrm{SSC}$ at $55^{\circ} \mathrm{C}$, and fewer signals were seen at $0.1-0.2 \times \mathrm{SSC}$ at this temperature. These conditions are appropriate for 30 mer oligoprobes. A further control included amplification with $\mathrm{HHV}-8$ primers and the use of a human papillomavirus type 16 (HPV-16) 30 mer probe (5'-GACTCCTG AGGAGAAGTCTGCCGTTACTGC-3').

For detection, the slides were incubated with avidin-horseradish peroxidase (1/100 in TBT with $5 \%$ skimmed dried milk (Cow and Gate)). Unbound conjugate was removed by washing twice in Tris buffered saline (TBS) for five minutes each. The slides were then incubated with AEC development reagent (Histostain-SP 
Table 1 Primers and probes for TaqMan PCR of HHV-8 ORF-26 and v-cyclin encoding regions

\begin{tabular}{|c|c|}
\hline Primer & Sequence \\
\hline KS1 ORF-26 & 5'-AGC CGA AAG GAT TCC ACC AT-3' \\
\hline KS2 ORF-26 & 5'-TCC GTG TTG TCT ACG TCC AG-3' \\
\hline TaqMan probe ORF-26 & 5'-F-CGC TAT TCT GCA GCA GCT GTT GGT GTA CCA-T-3' \\
\hline $\mathrm{v}-\mathrm{Cyclin} 1$ & 5'-ACC AGT TCA CTT TGC TAT GCC-3' \\
\hline $\mathrm{v}-\mathrm{Cyclin} 2$ & 5'-GCT TTT GTA ATC AGG GTG TTG AC-3' \\
\hline TaqMan probe v-cyclin & 5'-F- CAG ACT CCT TTT CCC GCC AAG AAC TTA TAG-T-3' \\
\hline$\beta$-Actin forward primer & 5'-TCA CCC ACA CTG TGC CCA TCT ACG A-3' \\
\hline$\beta$-Actin reverse primer & 5'-CAG CGG AAC CGC TCA TTG CCA ATG G-3' \\
\hline TaqMan probe $\beta$ actin & 5'-F-ATG CCC TCC CCC ATG CCA TCC TGC GT-T-3' \\
\hline
\end{tabular}

F, FAM; HHV-8, human herpesvirus 8; ORF, open reading frame; T, TAMRA; v-cyclin, viral cyclin.

Table 2 Primers and probes used for HHV-8 vIL-6, v-cyclin, and GPCR PCR

\begin{tabular}{ll}
\hline Primer/probe & Sequence \\
\hline v-Cyclin & F'-GCC GCC TGT AGA ACG GAA A-3' \\
Forward primer & 5'-GCT CAT TGC CCG CCT CTA-3' \\
Reverse primer & 5'-F-CAG GAA CCA ACA GCG CAC AGC C-T-3' \\
Probe & \\
v-IL-6 & 5'-CTC TTG CTG GTC GGT TCA CTG-3' \\
Forward primer & 5'-TGC CGG TAC GGT AAC AGA GG-3' \\
Reverse primer & 5'-F-CGG ACG CCC CCG AGT TTG AAA A-T-3' \\
Probe & \\
GPCR & 5'-GTG GTG CCT TAC ACG TGG AA-3' \\
Forward primer & 5'-GCG AGT TTA GGC AGA TAC CCA G-3' \\
Reverse primer & 5'-F-TTT TTG CAA GCA CCG ATC GCG GG-T-3' \\
Probe & \\
GAPDH & 5'-GAA GGT GAA CGG AGT-3' \\
Forward primer & 5'-GAA GAT GGT GAT GGG ATT TC-3' \\
Reverse primer & 5'-V-CAA GCT TCC CGT TCT CAG CC-T-3' \\
Probe &
\end{tabular}

F, FAM; GAPDH, glyceraldehyde-3-phosphate dehydrogenase; GPCR, G protein coupled receptor; HHV-8, human herpesvirus 8; T, TAMRA; V, VIC; v-IL-6, viral interleukin 6.

kit; Zymed Lab Inc, San Francisco, California, USA) for 10-20 minutes, which yielded a red signal.

Parallel immunocytochemistry for B cell markers (CD20; Dako) was carried out on all sections to confirm nodal and cellular localisation of the "in cell" PCR product. Combined immunocytochemistry and in cell PCR was not successful, as a result of the shearing of cells and tissue sections during thermocycling. The detection sensitivity of PCR in situ hybridisation for HHV-8 is one viral genome copy/cell. For our low copy detection we used the $5^{\prime}$ nuclease assay (TaqMan PCR) using primers and probes for ORF-26 and the v-cyclin regions of HHV-8 when analysing DNA samples and ORF-26, v-cyclin, v-IL-6, and G protein coupled receptor (GPCR) for the RNA samples (tables 1 and 2). The DNA samples were normalised using $\beta$-actin and the RNA samples with glyceraldehyde-3-phosphate dehydrogenase (GAPDH).

BC- 1 and BC-3 (body cavity lymphoma cell lines) were also analysed for HHV-8 using TaqMan quantitative analysis.

HHV-8 DETECTION BY ISH

Cloned fragments of HHV-8 (ORF-26 and $\mathrm{v}$-cyclin) were used; they were labelled with biotin and hybridisations were carried out overnight at $37^{\circ} \mathrm{C}$. Post hybridisation washes included SSC at different stringencies $(4 \times$ SSC at $22^{\circ} \mathrm{C}$ for five minutes, $2 \times \mathrm{SSC}$ at $55^{\circ} \mathrm{C}$ for five minutes, $1 \times \mathrm{SSC}$ at $55^{\circ} \mathrm{C}$ for five minutes), followed by a final wash in TBT for 10 minutes. Detection was carried out using the same protocol as for PCR-ISH. Positive control material included BC-1 and BC-3 cells.
Hybridisation efficiency was assessed using a biotin labelled alu repeat probe (blur 8).

HHV-8 DETECTION BY SOLUTION PHASE PCR DNA was extracted from three to four $5 \mu \mathrm{m}$ sections of paraffin wax embedded biopsies by treatment with xylene, digestion with proteinase $\mathrm{K}$, extraction with phenol/chloroform, and alcohol precipitation. The quality of the extracted DNA was controlled by PCR amplification of a $\beta$-actin gene fragment using the following primers: forward primer, 5'-TCA CCCACACTGTGCCCATCTACGA-3' and reverse primer, 5'-CAGCGGAACCGCTC ATTGCCAATGG-3'.

For HHV-8 detection, KS4 primer (5'AGCACTCGCAGGGCAGTACG-3') and KS5 primer (5'-GACTCTTCGCTGATG AACTGG-3'), derived from the putative minor capsid protein (homologue of ORF-26 of herpesvirus saimiri) were used and $100 \mathrm{ng}$ of starting DNA template was amplified for 25 cycles. To increase the sensitivity and verify the specificity of the amplicon obtained with these primers, $2 \mu \mathrm{l}$ of amplified product was reamplified (for 25 cycles) using internal primers KS1 (5'-AGCCGAAAGGATTCCACCAT-3') and KS2 (5'-TCCGTGTTGTCTACGTC CAG-3').

All positive cases were confirmed by amplification with non-overlapping primers derived from the major capsid protein of HHV-8 (ORF-25) using outer primers (5'-AGG CAACGTCAGATGTGAC-3' and 5'-GAAA TTACCCACGAGATCGC-3') and inner primers (5'-CATGGGAGTACATTGTCAG GACCTC-3' and 5'-GGAATTATCTCGCAG GTTGCC-3').

QUANTITATION OF HHV-8 VIRAL LOAD IN PAL BY TaqMan PCR

HHV-8 viral load in PAL biopsies was assessed by real time TaqMan PCR using the 7700 sequence detector (Perkin Elmer Applied Biosystems) and amplifying segments within the ORF-26 and the v-cyclin encoding region of the HHV-8 genome. This technique uses the $5^{\prime} \rightarrow 3^{\prime}$ endonucleolytic activity of AmpliTaq DNA polymerase, ${ }^{16-18}$ which enables the direct detection of the PCR product by the specific release of a fluorescent reporter molecule during the PCR reaction. ${ }^{19}$ The sensitivity of the TaqMan PCR is $1-2.5$ viral copies in $10^{6}$ contaminating human DNA sequences. For the detection of HHV-8, triplicate samples containing $100 \mathrm{ng}$ of starting DNA template were used. Magnesium chloride titration assays were performed initially to identify the optimal $\mathrm{MgCl}_{2}$ concentration for the reaction. Primers and the TaqMan probe were designed using "Primer Express", which determines the optimal annealing temperature $\left(\mathrm{Ta}_{\mathrm{OPT}}\right){ }^{20}$ The amplification mix consisted of $1 \times$ PCR buffer II (PE Biosystems), $4 \mathrm{mM} \mathrm{MgCl}_{2}, 200 \mu \mathrm{M}$ dNTPs (dCTP, dATP, dGTP), $400 \mu \mathrm{M}$ dUTP, $300 \mathrm{nM}$ forward and reverse primers, $200 \mathrm{nM}$ TaqMan probe, $0.025 \mathrm{U} / \mu \mathrm{l}$ AmpliTaq Gold DNA polymerase, and $0.01 \mathrm{U} / \mu 1$ AmpErase UNG (to prevent PCR cross contamination), using the primer and probe sets detailed below. 

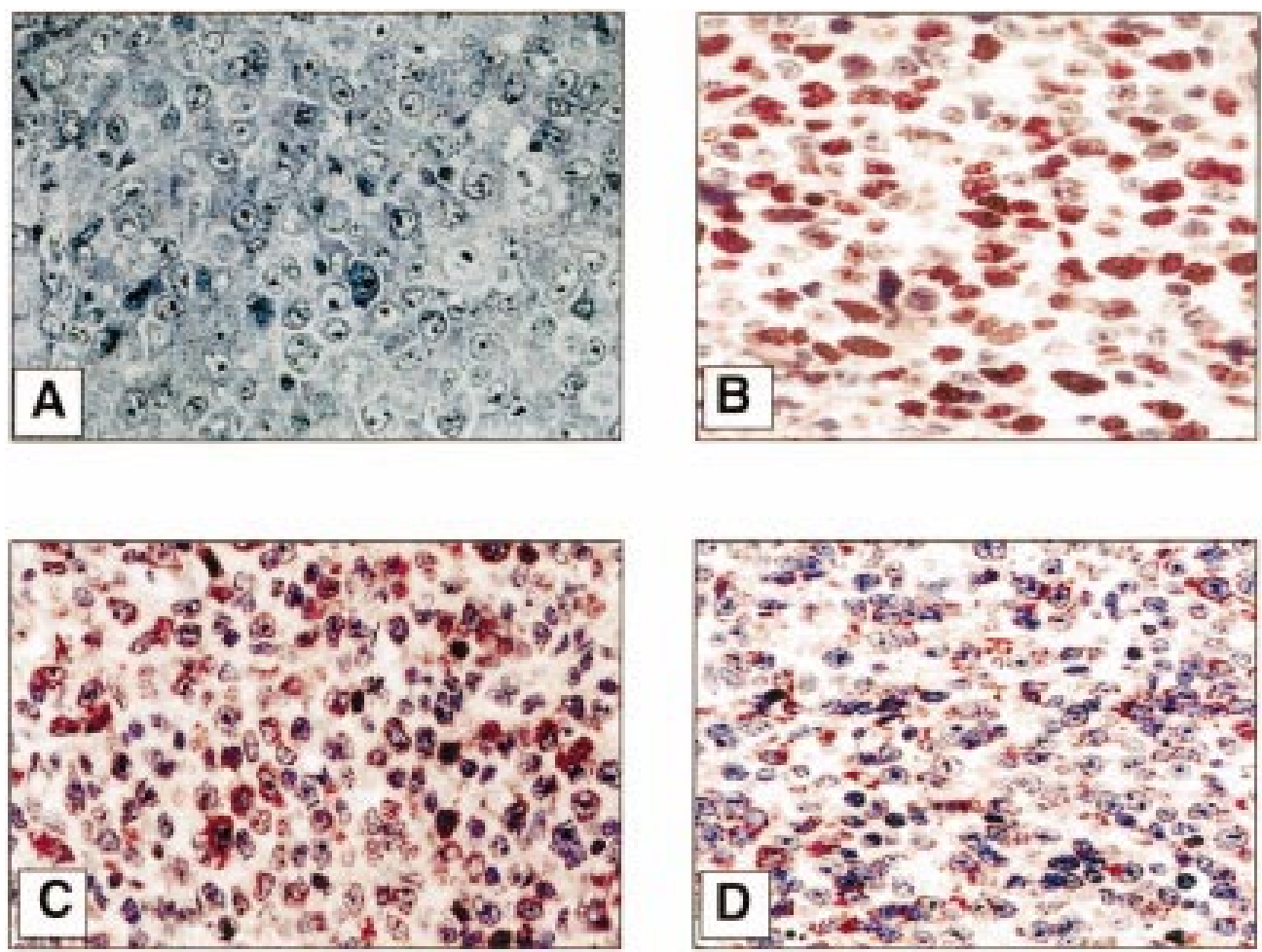

Figure l (A) Haematoxylin and eosin section of pyothorax associated lymphoma (PAL) showing pleomorphism and high mitotic index. (B) CD79a staining in the same case. (C) Epstein-Barr virus (EBV) encoded early RNA in situ hybridisation showing discrete signals in some PAL cells. (D) Parallel sections using a monoclonal antibody to the latent membrane protein 1 of EBV, confirming a similar distribution.

The quality of amplifiable DNA was assessed by $\beta$-actin TaqMan PCR.

Controls containing no template were also performed in triplicate for the ORF-26, $\mathrm{v}$-cyclin, and actin amplifications.

The following thermocycling conditions were applied: $50^{\circ} \mathrm{C}$ for two minutes (activation of UNG), $95^{\circ} \mathrm{C}$ for 10 minutes (activation of AmpliTaq Gold), $95^{\circ} \mathrm{C}$ for 15 seconds (denaturation), and $60^{\circ} \mathrm{C}$ for one minute (combined annealing and denaturation) for 40 cycles.

Specific product was detected using the Perkin Elmer 7700 sequence detector for real time PCR.

RNA TaqMan PCR

HHV-8 v-IL-6, v-cyclin, and GPCR PCR was carried out using the TaqMan PCR kit (PE Biosystems) using $0.1 \mathrm{U} / \mu \mathrm{l}$ RtTH polymerase, $1 \times 5 \mathrm{X}$ EZ buffer, $300 \mu \mathrm{M}$ dNTPs (dCTP,

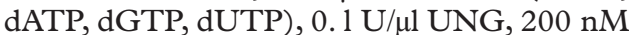
forward and reverse primers, $96.7 \mu \mathrm{M}$ GPCR and v-IL6 TaqMan probes, $5 \mu \mathrm{M}$ v-cyclin probe, and $3.5 \mathrm{mM} \mathrm{Mn}(\mathrm{OA})_{2}$.

Copy RNA (cRNA) standards were used for RNA quantitation. This was achieved using cloned HHV-8 v-IL6, GPCR, and v-cyclin fragments, which were then in vitro transcribed using $\mathrm{T} 7$ or $\mathrm{T} 3$ to give bidirectional cRNA isolates.

Controls with no template DNA were also performed in triplicate for the v-IL6, v-cyclin, GPCR, and GAPDH amplifications.

The following thermocycling conditions were applied: $50^{\circ} \mathrm{C}$ for two minutes (activation of UNG), $60^{\circ} \mathrm{C}$ for 30 minutes (reverse transcription), $95^{\circ} \mathrm{C}$ for five minutes (initial denaturation), and $94^{\circ} \mathrm{C}$ for 15 seconds and $60^{\circ} \mathrm{C}$ for one minute (denaturation and combined annealing), for 45 cycles.

Specific product was detected using the PE Biosystems 7700 sequence detector for reverse transcription real time PCR.

\section{Results}

In patient 1, CD45, CD79a, CD20, CD45RA, CD $43, \lambda$ light chain, and BCL-2 were all positive in $75-80 \%$ of the cells. The $\mathrm{Ki}-67$ index was high (identified in $70-80 \%$ of cells).

In patient 2, CD45, CD79a, CD20, $\kappa$ light chain, p53, and BCL-2 were positive in $70 \%$ of the cells. The Ki-67 index was high (identified in $90 \%$ of the cells).

EBER-ISH revealed hybridisation signals in approximately $30-40 \%$ of the cells (on serial section) (fig 1).

In patient $2, \mathrm{HHV}-8$ was not identified by solution phase PCR, but was identified using TaqMan PCR analysis, which yielded approximately $50-100$ HHV-8 copies $/ 2000$ cell genome equivalents. Approximately $35 \%$ of cells were positive by PCR-ISH (fig 1), showing discrete punctate signals in the cytoplasm of lymphomatous cells. Diffuse signals were also seen in a few cells $(<1 \%)$, indicating possible lytic infection. The sensitivity of the TaqMan PCR assay is 1 viral genome copy $/ 10^{6}$ contaminating sequences; the sensitivity of single round HHV-8 ORF-26 PCR is 1 copy $/ 10^{4}$ contaminating DNA sequences, with the nested format achieving sensitivities of 1 viral genome copy $/ 10^{5}$ contaminating sequences. The sensitivity of PCR-ISH is 1 viral genome copy/cell. Control reactions yielded appropriate results (fig 2), with the blur 


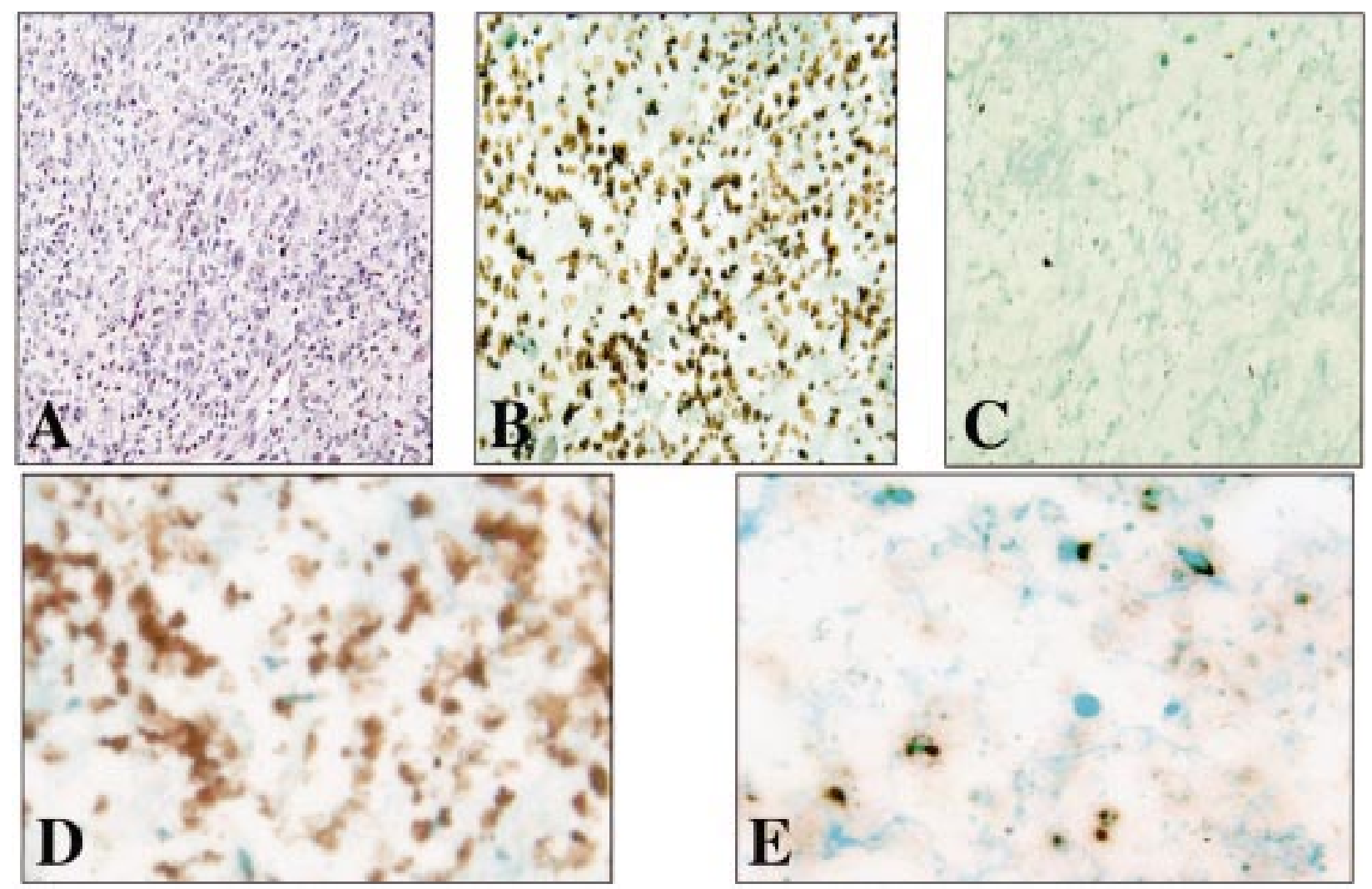

Figure 2 (A) Haematoxylin and eosin section of pyothorax associated lymphoma (PAL) (low power view). (B) Blur 8 alu probe confirming $100 \%$ hybridisation efficiency. (C) Irrelevant hybridisation using a human papillomavirus 16 specific probe illustrating no signals. (D) Human herpesvirus 8 (HHV-8) PCR in situ hybridisation showing diffuse signals in many PAL cells. (E) HHV-8 v-cyclin PCR-ISH showing discrete punctate signals in some cells, indicating latent infection.

8 alu repeat probe giving $100 \%$ signal in tissue sections, indicating $100 \%$ hybridisation efficiency. BC-1 and BC-3 cell lines (containing 50-100 HHV-8 genome copies/cell) yielded positive signals on ISH and PCR-ISH.

In patient 2, HHV-8 v-IL-6, GPCR, and $\mathrm{v}$-cyclin encoded transcripts could be identified using RNA TaqMan PCR. Results are compared with the expression of these regions

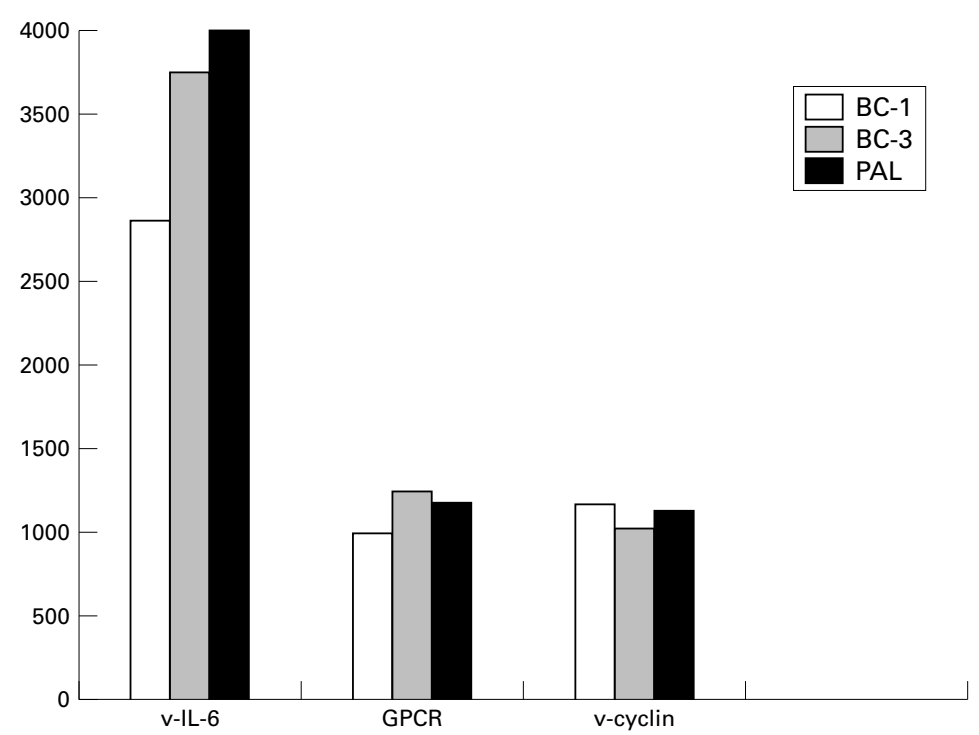

Figure 3 Quantitative TaqMan PCR analysis of human herpesvirus 8 gene expression in $B C-1$ and $B C-3$ cells and in pyothorax associated lymphoma (PAL). Results are expressed as copy RNA (cRNA) molecules/2000 cell extract equivalents. GPCR, G protein coupled receptor; v-cyclin, viral cyclin; v-IL-6, viral interleukin 6. in BC-1 and BC-3 cells (fig 3). v-IL6 expression was high in BC-1 cells, BC-3 cells, and in PALs, ranging from 2700 to $4000 \mathrm{cRNA}$ equivalents $/ 2000$ cell. Constitutive expression of GPCR and v-cyclin was lower, at around 1000 cRNA transcript equivalents. All results were gene dosage corrected using GAPDH.

\section{Discussion}

PAL occurs in approximately $2 \%$ of patients with chronic pyothorax, 22-55 years after artificial pneumothorax to control lung tuberculosis or tuberculous pleuritis. Epidemiological studies in Japan suggest that the risk of lymphoma in these patients is 3000 times higher than in the general population. ${ }^{21} \mathrm{Al}-$ though rare cases of anaplastic large cell and $\mathrm{T}$ cell rich $\mathrm{B}$ cell morphology have been described, our cases were representative of the more usual diffuse large B cell immunoblastic phenotype, and both demonstrated clonal rearrangements $(\kappa$ and $\lambda$ light chain restriction), as documented previously. ${ }^{12} 223$ The Ki-67 index was high $(80-90 \%$ of cells positive), indicating high cell turnover.

Viral studies suggest a causal association with EBV. $^{14212324}$ Our results also confirmed the presence of latent type III EBV infection. HHV-8 has been reported recently in association with primary effusion lymphomas (body cavity based lymphomas) and this has led to speculation regarding its involvement in PALs. ${ }^{25}$ HHV-8 is the well described first member of the Rhadinovirus family of $\gamma$ herpesviruses. ${ }^{26}$ It is also described in all types of Kaposi's sarcoma, 
Castleman's disease, AIDS central nervous system lymphoma, and multiple myeloma. To date, at least 14 reading frames of $\mathrm{HHV}-8$ are clearly homologous to cellular genes known to encode proteins involved in inflammation and tumour development: v-IL-6, v-cyclin, GPCR, BCL-2, the IL-8 receptor, macrophage inflammatory protein 1 (MIP-1), and MIP-2

An association between PAL and HHV-8 remains controversial. Ascani et al reported an association with $\mathrm{HHV}-8,{ }^{11}$ but Cesarman et al did not detect the virus in 12 Japanese and two French cases of PAL. ${ }^{27}$ We investigated the presence of HHV-8 using solution phase PCR and in situ PCR, confirming and quantifying our results using the highly sensitive real time quantitative TaqMan PCR technique. We identified the virus in one of two cases of PAL (50-100 viral copies/2000 DNA cell equivalents). We recognise that our sample number is very small, but feel that these results are relevant given the sensitivity (detects 1 copy of viral genome $/ 10^{5} \mathrm{DNA}$ cell extract equivalents) and specificity of the TaqMan reaction. We suggest that earlier studies not identifying HHV-8 suffer from a lack of sensitivity.

The examination of the expression patterns of HHV-8 encoded genes (v-IL-6, GPCR, and $\mathrm{v}$-cyclin) demonstrated a similar degree of expression in both PALs and primary effusion lymphoma cell lines (BC-1 and BC-3), suggesting that there is a similar mechanism of induction and conservation of the effusion phenotype in both of these entities. Although both entities are pleural cavity based, are associated with EBV, show immunoglobulin restriction, and express CD45 antigen, they have many differing features-primary effusion lymphomas show diffuse large cell morphology (with features intermediate between immunoblastic or anaplastic large cell lymphoma morphology) and have a B cell genotype, with evidence of immunoglobulin gene rearrangements. CD45, CD30, CD38, CD71, and human major histocompatibility complex DR antigen (HLADR) are expressed in the absence of other B or $\mathrm{T}$ cell lineage restricted antigens, whereas PALs have a diffuse large cell (predominantly immunoblastic) morphology. Tumour cells are $B$ cell or null in type and negative for CD30. ${ }^{122}{ }^{28-30}$ Of interest, the BC-3 cell line is not infected by EBV, whereas the BC-1 cell line and PALs are, suggesting that EBV is not the agent responsible for the effusion phenotype.

The presence of HHV-8 in one of two patients with PAL raises interesting questions in relation to the pathobiology of the condition. Clearly, the results indicate that HHV-8 is not an obligate pathogen, necessary for the effusion phenotype, but might contribute to it by its secretion of specific cytokines. The HHV-8 encoded cytokine pattern in BC- 1 and BC-3 cells is similar, suggesting a common pathogenic mechanism in these lesions. Further studies involving larger numbers of patients should delineate the relation between HHV-8, PALs, and the effusion phenotype.

We wish to thank the Irish Cancer Society and the Health Research Board for their continued support.
1 Iuchi K, Ichimiya A, Akasha A, et al. Non Hodgkin's Iuchi K, Ichimiya A, Akasha A, et al. Non Hodgkin's
lymphoma of the pleural cavity developing from long lymphoma of the pleural cavity developing

2 Iuchi K, Aozasa K, Yamamoto S, et al. Non Hodgkin's lymphoma of the pleural cavity developing from long standing pyothorax. Summary of the clinical and pathological findings in thirty seven cases. Fpn f Clin Oncol 1989; 19:249-57.

3 Aozasa K, Ohsawa M, Iuchi K, et al. Artificial pneumothorax as risk factor for the development of pleural lymphoma. fpn F Cancer Res 1993;84:55-7.

4 Minami M, Kawauchi N, Yoshikawa K, et al. Malignancy associated with chronic empyema: radiologic assessment. Radiology 1991;178:417-23.

5 Fresq G, Kabbani J, Mellat M, et al. Diagnostiq d'une masse pleuro-parietale chez un patient aux antecedents de tuberpleuro-parietale chez un patient aux antecedents de

6 Hubert D, Lacronique J, Vacher MC, et al. Lymphome pulmonaire primitif sur cicatrice. Presse Med 1985;14:1516.

7 Luther VR, Schoefer G, Sporman H, et al. Malignes immunoblastisches Lymphom unter einer Pneumolysenschwarte mit Pleuraempyem. Gesamte Inn Med 1984;36:399-402

8 Martin A, Capron F, Liguory-Brunaud MD, et al. EpsteinBarr virus associated primary malignant lymphomas of the pleural cavity occurring in longstanding pleur

Molinie V, Pouchot J, Navratil E, et al. Primary Epstein-Barr virus related non-Hodgkins lymphoma of the pleural cavity following long standing tuberculous empyema. Arch Pathol

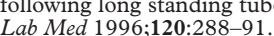

10 Taniere PH, Manai A, Charpentier R, et al. Pyothoraxassociated lymphoma: relationship with Epstein-Barr virus, human herpes virus- 8 and body cavity-based lymphomas. Eur Respir f 1998;11:779-83.

11 Ascani S, Piccioli M, Poggi S, et al. Pyothorax-associated lymphoma: description of the first two cases detected in Italy. Ann Oncol 1997;8:1133-8.

12 Nakamura S, Sasajima Y, Koshikawa T, et al. Ki-1 (CD30) positive anaplastic large cell lymphoma of $\mathrm{T}$ cell phenotype developing in association with longstanding tuberculous virus genome in the tumour cells. Hum Pathol 1995;26: 1382-5.

13 Mori N, Yatabe Y, Narita M, et al. Pyothorax-associated lymphoma. An unusual case with biphenotypic character of $\mathrm{B}$ and T cells. Am 7 Surg Pathol 1996;20:760-6.

14 Sasajima Y, Yamabe H, Kobashi Y, et al. High expression of the Epstein-Barr virus latent protein EB nuclear antigen-2 on pyothorax-associated lymphomas. Am $\mathcal{F}$ Pathol 1993; 143:1280-5

15 Ramasamy I, Brisco M, Morley A. Improved PCR method for detecting monoclonal immunoglobulin heavy chain rearrangement in B cell neoplasms. F Clin Pathol 1992;45: $770-5$.

16 Lawyer FC, Stoffel S, Saiki RK, et al. Isolation, characterisation, and expression in Escherichia coli of the DNA polymerase gene from the extreme thermophile, Thermus polyuaticus. F Biol Chem 1989;264:6427-37.

17 Holland PM, Abramsom RD, Watson R, et al. Detection of specific polymerase chain reaction product by utilizing the polymerase. Proc Natl Acad Sci U S A 1991;88:7276-80.

18 Lyamichev V, Brow MAD, Dahlberg JE. Structure-specific endonucleolytic cleavage of nucleic acids by eubacterial DNA polymerases. Science 1993;260:778-83.

19 Lee LG, Connell CR, Bloch W. Allelic discrimination by nick-translation PCR with fluorogenic probes. Nucleic Acids Res 1993;21:3761-6.

20 Rhoads RE, Optimization of the annealing temperature for DNA amplification in vitro. Nucleic Acids Res 1990;18: 6409-12.

21 Fukayama M, Hayashi Y, Ooba $\mathrm{T}$, et al. Pyothorax associated lymphoma: development of Epstein-Barr virusassociated lymphoma: development of Epstein-Barr virusPathol Int 1995;45:825-31.

22 Ibuka T, Fukayama M, Hayash Y, et al. Pyothorax-associated pleural lymphoma. A case evolving from T-cell-rich lymphoid infiltration to overt B-cell lymphoma in association with Epstein-Barr virus. Cancer 1994;73:738-44

23 Aozasa K, Ohsawa M, Kanno H. Pyothorax associated ymphoma: a distinctive type of lymphoma strongly associated with Epstein-Barr virus. Adv Anat Pathol 1997;4:58-63.

24 Fukayama M, Ibuka T, Hayashi Y, et al. Epstein-Barr virus in pyothorax associated pleural lymphoma. Am $\mathcal{F}$ Pathol 1993;143:1044-9.

25 Cesarman E, Chang Y, Moore PS, et al. Kaposi's sarcomaassociated herpesvirus-like DNA sequences in AIDSassociated herpesvirus-like DNA sequences in AIDSrelated body-cav

26 Moore PS, Chang Y. Detection of herpesvirus-like DNA sequences in Kaposi's sarcoma in patients with and those without HIV infection. N Engl F Med 1995;332:1181-4

27 Cesarman E, Nador RG, Aozasa K, et al. Kaposi's sarcoma associated herpes virus in non-AIDS-related lymphomas occurring in body cavities. Am f Pathol 1996;149:53-7.

28 Jaffe ES. Primary body cavity-based AIDS-related lymphomas. Am f Clin Pathol 1996;105:141-3.

29 Ansari MQ, Dawson B, Nador R, et al. Primary body cavitybased AIDS-related lymphomas. Am F Clin Pathol 1996; 105:221-9.

30 Espiritu E, Green I, Ladanyi M, et al. Primary lymphomatous effusions in AIDS: a morphological, immunophenotypic, and molecular study. Mod Pathol 1995;8:39-45. 